\title{
Psychometric evaluation of the Work Readiness Questionnaire in schizophrenia
}

\author{
Steven G. Potkin, ${ }^{*}$ Dragana Bugarski-Kirola, ${ }^{2}$ Chris J. Edgar, ${ }^{3}$ Sherif Soliman, ${ }^{2}$ \\ Stephanie Le Scouiller, ${ }^{4}$ Jelena Kunovac, ${ }^{5}$ Eugenio Miguel Velasco, ${ }^{6}$ and \\ George M. Garibaldi *
}

\footnotetext{
${ }^{1}$ Professor, Department of Psychiatry and Human Behavior, University of California-Irvine, Orange, California, USA

${ }^{2}$ Neuroscience Product Development (PDN), F. Hoffmann-La Roche Ltd, Basel, Switzerland

${ }^{3}$ Neuroscience Product Development (PDN), Roche Products Ltd., Welwyn Garden City, United Kingdom

${ }^{4}$ Product Development, Biometrics, Roche Products Ltd., Welwyn Garden City, United Kingdom

${ }^{5}$ Medical Director, Excell Research, Inc., Oceanside, California, USA

${ }^{6}$ Resolution Psychopharmacology Research Institute, Mendoza, Argentina
}

Objective/Introduction. Unemployment can negatively impact quality of life among patients with schizophrenia. Employment status depends on ability, opportunity, education, and cultural influences. A clinician-rated scale of work readiness, independent of current work status, can be a valuable assessment tool. A series of studies were conducted to create and validate a Work Readiness Questionnaire (WoRQ) for clinicians to assess patient ability to engage in socially useful activity, independent of work availability.

Methods. Content validity, test-retest and inter-rater reliability, and construct validity were evaluated in three separate studies.

Results. Content validity was supported. Cronbach's $\alpha$ was 0.91 , in the excellent range. Clinicians endorsed WoRQ concepts, including treatment adherence, physical appearance, social competence, and symptom control. The final readiness decision showed good test-retest reliability and moderate inter-rater reliability. Work readiness was associated with higher function and lower levels of negative symptoms. Low positive and high negative predictive values confirmed the concept validity.

Discussion. The WoRQ has suitable psychometric properties for use in a clinical trial for patients with a broad range of symptom severity. The scale may be applicable to assess therapeutic interventions. It is not intended to assess eligibility for supported work interventions.

Conclusions. The WoRQ is suitable for use in schizophrenia clinical trials to assess patient work functional potential.

\footnotetext{
${ }^{*}$ Addresses for correspondence: Steven G. Potkin, University of California-Irvine, Orange, CA, USA. (Email: sgpotkin@uci.edu; sgpotkin@gmail.com) George M. Garibaldi, Global Head of Neuroscience Product Development - PDN, F. Hoffmann-la Roche, 4070-Basel, Switzerland (Email: george.garibaldi@roche.com).

This research was supported by F. Hoffmann-La Roche Ltd. The authors would like to thank the following principle investigators who participated in the various validation steps described in this article: USA Miranda Chakos, Alla Gourov, Barbara Hartsfield; Serbia: Nadja Maric; UK: Nicholas Beecroft; Brazil: Helio Elkis, Sandra Ruschel; Japan: Yoshio Hirayasu; Mainland China: Huafang Li; Taiwan: Tsuo-Hung Lan. The authors also acknowledge the prestudy raters in the centers led by the following individuals: Sarah Atkinson, Anders Berntsson, Ricardo Corral, Johnny Edrozo, John Geddes, Mark Hernandez, MaryAnn Knezevic, Alex Koplowitz, Nils Lindefors, Jean-PierreLindenmayer, Eva Lindstrom, Joseph McEvoy, Vishaal Mehra, Carlos Morra, Mark Novitsky, Bhatia Prakash, Scott Segal, Manuel Velasco, Peter Ventre, Nashimath Yadalam. The authors thank Mary Kujawa, Nick Marsh, Ruth Middleton, Kisook Yoo, and Sherif Soliman, all formerly of F. Hoffmann-La Roche, for their contributions to these studies, and Shichun Ling for editorial support.
}

Received 16 April 2014; Accepted 23 May 2014; First published online 1 October 2014

Key words: clinical outcomes research, employment, function, readiness for work, schizophrenia.

\section{Introduction}

Unemployment among patients with schizophrenia is high. ${ }^{1}$ The Worldwide Schizophrenia Outpatient Health Outcomes (W-SOHO) study measured clinical and functional remission in 11,078 outpatients with schizophrenia from 37 countries. Unemployment rates were $55 \%$ in patients with functional remission and $\mathbf{8 8 \%}$ in patients with neither functional nor clinical remission. ${ }^{2}$ In contrast, the global unemployment rate is $6.2 \% .{ }^{3}$ Even for subpopulations with high unemployment, such as youths (15-24 years) in the Middle East and North Africa, the rate is only $25 \%{ }^{3}$ 
Unemployment affects patient quality of life due to insufficient daytime activities, lack of company and relationships, and few opportunities to increase selfesteem. Family and societal concerns focus on long-term financial impact and patients' ability to live independently. ${ }^{4}$ A survey of patients, relatives, physicians, and payers showed payers ascribing the highest value to treatment goals affecting costs, including employment. ${ }^{5}$ Thus, ability to work is a legitimate schizophrenia treatment target. Attempts to increase employment among those with schizophrenia have included supported employment and a variety of vocational rehabilitation approaches.

One way to assess work ability is to evaluate employment status. However, employment status among patients with schizophrenia is hindered by work availability, and may be influenced by socioeconomic factors and cultural influences including disability rules and the stigma associated with mental illness. Previous work history and education also predict work status. ${ }^{6}$ A surrogate endpoint-the ability to work-rather than actual employment, may be a measure of success of an intervention independent of personal history, socioeconomics, or cultural factors.

Functional status is correlated with work status in patients with schizophrenia; eg, the University of California-San Diego Performance-based Skills Assessment (UPSA) scores are correlated with level of engagement in work, volunteering, and schooling. ${ }^{7}$ The brief UPSA (UPSA-B) also predicted work status. ${ }^{8}$ However, these measures focus on prerequisite activities for employment (eg, ability to use a telephone or public transport) and were not developed to assess clinical factors influencing the ability to get and keep a job (eg, the ability to relate to peers/supervisors), nor has research considered work exclusively as the capacity for independent, paid employment. While there is considerable value in supported employment and the recovery movement approaches, we focused on the capacity to independently perform activities that could merit pay. To our knowledge, no clinician-rated assessment of the ability to work exists for patients with serious mental illness. Our objective was to develop such a scale-the Work Readiness Questionnaire (WoRQ)-and evaluate its utility as a clinical trials tool.

\section{Methods}

We set out to create and validate a work readiness questionnaire independent of work status that is easy to use and practical for clinicians to assess and rate patient ability to engage in socially useful activity that could merit pay. The concept was based on the "readiness for discharge" questionnaire 9 and was guided by clinical experience. The questionnaire was validated for (a) content validity, (b) reliability, and (c) construct validity.

\section{Experimental methods}

Study 1: Content validity

The WoRQ is composed of 7 items (Table 1) that capture a patient's readiness to work based on capacity to initiate and maintain useful activity that could merit pay, leading to a final dichotomous work readiness judgment. The questionnaire is completed using progress notes, medical records, and input from mental health professionals, family members, or caregivers (Table 1). The 7 items are graded as follows: "strongly agree," "agree," "disagree," or "strongly disagree," based on a patient's ability to conduct daily activities, interact with others, and adhere to treatment, and based on others' perceptions of patient appearance, behavior, and impulse control. These 7 items are not totaled but are used to aid in reaching the dichotomous work readiness judgment.

TABLE 1. Work Readiness Questionnaire (WoRQ v4.0). Instructions: This instrument defines work as any useful activity that could merit pay, and does not include work that requires an unusual level of supervision or rehabilitation work. Activities of daily living can include using public transportation and meal preparation, in addition to basic self-care. The judgment on work readiness is independent of whether a job is available to the patient. The 7 items below are provided as a guide for answering the final question in the box. Please read each statement below and select a response based on all sources of information available. The final question is a global judgment and not the sum of the previous items.

\begin{tabular}{|c|c|c|c|c|c|}
\hline & Decrintion & Strongly agree & Agree & Disagree & Strongly disagree \\
\hline Item 1 & The patient generally adheres to a treatment plan, including medication. & & & & \\
\hline Item 2 & The patient is able to carry out activities of daily living. & & & & \\
\hline Item 3 & The patient is able to consistently keep appointments and schedules with only minimal assistance. & & & & \\
\hline Item 4 & $\begin{array}{l}\text { The patient would have adequate impulse control when interacting with authority figures, peers or } \\
\text { coworkers, and potential customers. }\end{array}$ & & & & \\
\hline Item 5 & The patient's behavior would not make others uncomfortable in a work situation. & & & & \\
\hline Item 6 & The patient's appearance would not make others uncomfortable in a work situation. & & & & \\
\hline \multirow[t]{2}{*}{ Item 7} & The patient's current symptoms would not interfere with the ability to hold a job. & & & & \\
\hline & Based on your clinical judgment, is this patient ready for work? & \multicolumn{2}{|l|}{ Yes } & \multicolumn{2}{|r|}{ No } \\
\hline
\end{tabular}


TABLE 2. Test-retest reliability between session I (baseline) and session II (3-4 weeks later)

\begin{tabular}{|c|c|c|c|}
\hline WoRQ items & $\begin{array}{l}\text { Session I } \\
\text { mean (SD) }\end{array}$ & $\begin{array}{l}\text { Session II } \\
\text { mean (SD) }\end{array}$ & $\operatorname{ICC}(1,1)^{\mathrm{a}}$ \\
\hline 1. The patient generally adheres to a treatment plan including medication. & $1.98(0.601)$ & $1.97(0.517)$ & 0.42 \\
\hline 2. The patient is able to carry out activities of daily living. & $2.28(0.769)$ & $2.29(0.679)$ & 0.58 \\
\hline $\begin{array}{l}\text { 3. The patient is able to consistently keep appointments and schedules with only minimal } \\
\text { assistance. }\end{array}$ & $2.36(0.828)$ & $2.38(0.711)$ & 0.57 \\
\hline $\begin{array}{l}\text { 4. The patient would have adequate impulse control when interacting with authority figures, } \\
\text { peers or coworkers, and potential customers. }\end{array}$ & $2.43(0.763)$ & $2.36(0.754)$ & 0.60 \\
\hline 5. The patient's behavior would not make others uncomfortable in a work situation. & $2.75(0.759)$ & $2.67(0.737)$ & 0.66 \\
\hline 6. The patient's appearance would not make others uncomfortable in a work situation. & $2.53(0.798)$ & $2.58(0.752)$ & 0.64 \\
\hline 7. The patient's current symptoms would not interfere with the ability to hold a job. & $3.11(0.742)$ & $3.22(0.597)$ & 0.45 \\
\hline
\end{tabular}

Content validity was established cross-culturally via qualitative analyses of interviews with 11 practicing clinicians to gather insights on schizophrenia and work readiness and obtain feedback on the preliminary WoRQ. Respondents included psychiatrists and psychiatric nurses from clinical sites in North America, Asia, Europe, and Latin America. Potential respondents were selected based on the following key criteria: schizophrenia experts working closely with patients, fluency in English, and willingness to participate in a 1-hour interview to discuss respondents' experiences with schizophrenia patients. The literature on positive and negative symptoms, and work readiness research in schizophrenia was reviewed using MEDLINE, PROQOLID, and Mapi Values (Mapi Research Institute). A literature-based conceptual framework was developed to guide respondent telephone interviews. Data analyses included response coding and comparing/contrasting to the conceptual framework and original questionnaire. The questionnaire was subsequently revised and finalized for use in studies 2 and 3 .

\section{Study 2: Inter-rater and test-retest reliability}

Ten practicing psychiatrists assessed 12 videotaped schizophrenia patients twice within 4 weeks. Patients were recruited from a single U.S. center by advertising within a network of colleagues and group homes. All were outpatients, not involved in a clinical trial, met diagnostic criteria for schizophrenia (Diagnostic Statistical Manual of Mental Disorders, Fourth Edition [DSMIV]), and were heterogeneous for psychopathology, disability, gender, ethnicity/race, marital status, and employment status/background. Treatment records were required. Patients and caregivers gave informed consent and received compensation for participating. Questionnaire rating instructions were provided before
Session I. Patients were rated in a non-proscribed order using an interactive DVD, including all 12 patient videos and supporting information. Raters reviewed each video; supporting interviews (caregivers, mental health professionals); and the patient's personal, medical, and psychiatric history and current treatment. Raters completed the WoRQ. This process was repeated after 4 weeks, and raters did not have access to original ratings (Table 2).

\section{Study 3: Construct validity}

This was a global, cross-sectional, observational, standalone study. Adult patients with schizophrenia $(\mathrm{n}=200)$ received study information, gave consent, and had eligibility confirmed before a data collection visit. The patient and second respondent (family member/caregiver/clinical staff) were interviewed by a clinician who completed assessments. Raters were free to judge how to evaluate conflicting information from patients and second respondents in the work readiness evaluation. Of the recruited patients, $25 \%$ were working independently at the time of assessment. Data were collected for demographics, health/psychiatric history, work status, work readiness (WoRQ), function (Global Assessment of Functioning $[\mathrm{GAF}],{ }^{10}$ Level of Functioning $\left.[\mathrm{LoF}]^{11}\right]$ ), negative symptoms (Negative Symptom Assessment-4item version [NSA-4] ${ }^{12}$ ), and symptom severity (Clinical Global Impression of Severity of Negative Symptoms [CGI-S-N] ${ }^{13}$ ]) (Table 2). All assessments were completed by the same rater, with the WoRQ assessed prior to the GAF, LoF, NSA-4, and CGI-S-N.

\section{Statistical methodology}

Content validity

This was established as described above. 
TABLE 3. Test-retest reliability between session I (baseline) and session II (3-4 weeks later) on work readiness status

\begin{tabular}{|c|c|c|c|c|c|c|c|c|c|c|c|}
\hline \multirow[b]{3}{*}{ Dichotomous variable } & \multicolumn{4}{|c|}{ Session I } & \multicolumn{4}{|c|}{ Session II } & \multirow[b]{3}{*}{$\%$ agreement } & \multirow[b]{3}{*}{$\kappa$} & \multirow[b]{3}{*}{ Tetrachoric Correlation } \\
\hline & \multicolumn{2}{|c|}{ Ready for work } & \multicolumn{2}{|c|}{ Not ready for work } & \multicolumn{2}{|c|}{ Ready for work } & \multicolumn{2}{|c|}{ Not ready for work } & & & \\
\hline & $n$ & $(\%)$ & $\mathrm{n}$ & $(\%)$ & $n$ & $(\%)$ & $\mathrm{n}$ & $(\%)$ & & & \\
\hline Work readiness status & 24 & $(20.0)$ & 96 & $(80.0)$ & 21 & $(17.5)$ & 99 & (82.5) & 84.17 & 0.48034 & 0.7342 \\
\hline
\end{tabular}

\section{Test-retest reliability}

Test-retest reliability was calculated using intra-class correlation coefficients (ICCs) $(1,1)$ in Study 2 for the initial items from Sessions I and II for each rater, where ICCs were interpreted as $0-0.2$, poor; $0.3-0.4$, fair; $0.5-0.6$, moderate; 0.7-0.8, strong; and >0.8, excellent/near perfect reliability. For the dichotomous work readiness question, a tetrachoric correlation was performed to evaluate reproducibility between Sessions I and II.

\section{Inter-rater reliability}

Inter-rater reliability was assessed at each session using ICCs for items 1-7 (rated 1-4) in Study 2. Following Shrout and Fleiss's notation, ${ }^{14^{*}}$ score reproducibility among 10 raters for each item was tested using singlemeasure reliability ICC $(2,1)$, where ICCs assess rating reliability by comparing the variability of different ratings of the same item to the total variation across all ratings and subjects. This ICC $(2,1)$ application differs from the ICC $(1,1)$ used for test-retest reliability. ICC $(2,1)$ values were interpreted as per test-retest. For the dichotomous work readiness question, inter-rater reliability was assessed using percentage agreement and Fleiss's $\kappa$ for multiple raters (ranging from $0=$ chance to 1 = complete agreement) and tetrachoric correlation for observed dichotomous or binary variables.

\section{Construct validity}

GAF score, LoF score, NSA-4 total score, and CGI-S-N rating were used to assess construct validity. Means were tested using $t$ tests for the 2 levels of work readiness (yes/ no). Cross-tabulations and Fisher exact tests were used to estimate the relationship between work readiness and categorical aspects of the measures. Spearman correlations between work readiness judgments and the criterion

\footnotetext{
* Regarding the notation of Shrout and Fleiss, the first number refers to the type of analysis of variance (ANOVA: random versus mixed model) and the number of factors included in the ANOVA, and the second number refers to whether the reliability is for a single rating or for an average of ratings obtained from more than one rater. ICC $(1,1)$ corresponds to a one-way ANOVA with patient included as a random factor where each patient is rated by a set of raters that is randomly selected from a larger population. ICC $(2,1)$ corresponds to a two-way ANOVA with patients and raters included as random factors in order to assess whether the ratings of one rater are apt to be the same as for another, for individual patients.
}

measures were calculated (excluding LoF score). Sensitivity, specificity, and positive and negative predictive value for actual work status were also evaluated.

\section{Internal reliability}

Internal consistency, or how the items relate to the underlying construct, of the WoRQ items was measured by Cronbach's $\alpha .{ }^{15}$ Values $\geq 0.7$ are generally interpreted as indicating good reliability, and those $\geq 0.9$ are indications of excellent reliability. ${ }^{16}$

\section{Relationship between WoRQ items and overall rating}

Regression analyses evaluated correlations between individual WoRQ items and overall WoRQ work readiness ratings.

\section{Results}

\section{Study 1: Content validity}

In-depth exploratory interviews with clinical experts guided preliminary questionnaire revisions and supported its content validity. Telephone interviews captured the perceived importance of patients' (a) medication adherence, (b) insight, (c) desire to work, (d) physical appearance, (e) social competence, and (f) positive symptom control. Refinements to the preliminary WoRQ included separating behavior and appearance as 2 items, item resequencing for logic and coherence, and language changes to orient clinicians to the concept in each item, with examples illustrating practice patterns in respondents' geographic areas.

\section{Study 2: Test-retest reliability}

Test-retest reliability for the initial questions (1-7) was moderate: ICCs $(1,1)$ ranged from $0.42-0.66$ (Table 2 ). For the final work readiness judgment, test-retest reliability was good (tetrachoric correlation, 0.73) (Table 3).

\section{Study 2: Inter-rater reliability}

There was good agreement among raters in the assessment of work readiness ( $>70 \%$ at first rating/Session I; $>80 \%$ at second rating/Session II). Agreement by $\kappa$ statistic and tetrachoric correlation was fair to moderate (0.32 and 0.53 at Session I and 0.43 and 0.69 at Session II, respectively). 


\begin{tabular}{|c|c|c|c|c|c|c|}
\hline \multirow[b]{2}{*}{ WoRQ items } & \multicolumn{3}{|c|}{$\begin{array}{l}\text { Session } \mathrm{I} \\
\mathrm{n}=10 \text { raters and } \mathrm{n}=12 \text { patients }\end{array}$} & \multicolumn{3}{|c|}{$\begin{array}{c}\text { Session } \| \\
\mathrm{n}=10 \text { raters and } \mathrm{n}=12 \text { patients }\end{array}$} \\
\hline & \multicolumn{3}{|c|}{$\operatorname{ICC}(2,1)^{\mathrm{a}}$} & \multicolumn{3}{|c|}{$\operatorname{ICC}(2,1)^{\mathrm{a}}$} \\
\hline $\begin{array}{l}\text { 1. The patient generally adheres to a treatment plan including } \\
\text { medication. }\end{array}$ & \multicolumn{3}{|c|}{0.23} & \multicolumn{3}{|c|}{0.29} \\
\hline 2. The patient is able to carry out activities of daily living. & \multicolumn{3}{|c|}{0.42} & \multicolumn{3}{|c|}{0.43} \\
\hline $\begin{array}{l}\text { 3. The patient is able to consistently keep appointments and } \\
\text { schedules with only minimal assistance. }\end{array}$ & \multicolumn{3}{|c|}{0.37} & \multicolumn{3}{|c|}{0.40} \\
\hline $\begin{array}{l}\text { 4. The patient would have adequate impulse control when } \\
\text { interacting with authority figures, peers or coworkers, } \\
\text { and potential customers. }\end{array}$ & \multicolumn{3}{|c|}{0.43} & \multicolumn{3}{|c|}{0.40} \\
\hline $\begin{array}{l}\text { 5. The patient's behavior would not make others uncomfortable } \\
\text { in a work situation. }\end{array}$ & \multicolumn{3}{|c|}{0.47} & \multicolumn{3}{|c|}{0.52} \\
\hline $\begin{array}{l}\text { 6. The patient's appearance would not make others uncomfortable } \\
\text { in a work situation. }\end{array}$ & \multicolumn{3}{|c|}{0.40} & \multicolumn{3}{|c|}{0.54} \\
\hline $\begin{array}{l}\text { 7. The patient's current symptoms would not interfere with } \\
\text { the ability to hold a job. }\end{array}$ & \multicolumn{3}{|c|}{0.35} & \multicolumn{3}{|c|}{0.24} \\
\hline Dichotomous variable & $\%$ agreement & $\kappa$ & Tetrachoric correlation & $\%$ agreement & $\kappa$ & Tetrachoric Correlation \\
\hline Work readiness status & 78.15 & 0.31713 & 0.53 & 83.52 & 0.42921 & 0.69 \\
\hline
\end{tabular}

This apparent discrepancy in agreement between good percentage agreement and fair-to-moderate $\kappa$ and ICC may reflect the different underlying assumptions of the statistical tests. The $\kappa$ statistic estimates the level of agreement exceeding that expected by chance and assumes randomness in the ratings, or guessing. Since raters are not expected to guess at responses, this estimate may be conservative. The ICC $(2,1)$ was calculated according to the notation of Shrout and Fleiss, as opposed to that more commonly reported in the literature, which uses an average measure accounting for less variability. Thus ICC $(2,1)$ is a more conservative approach comparatively. Moderate agreement was seen among raters in their assessment of the 7 items preceding the work readiness judgment, with ICCs $(2,1)$ of $0.23-0.54$. Levels of agreement improved from Session I to Session II (Table 4).

\section{Study 3: Construct validity}

Patients were predominantly male (68.5\%). Fewer males $(38.7 \%)$ than females $(55.6 \%)$ were rated ready to work. Age was similar in those rated ready to work (44.6, SD $12.03)$ and not ready to work (45.6, SD 12.07). With respect to educational background, the highest percentage of patients in both readiness groups had a high school diploma or equivalent $(25.0 \%$ ready; $38.4 \%$ not ready). However, a greater percentage of those ready to work $(14.8 \%)$ than not ready $(4.5 \%)$ had a college degree (Table 5).
Mean GAF scores were significantly higher $(p<0.0001)$ in patients rated ready to work $(61.8, \mathrm{SD}$ 9.39) than those rated not ready (48.0, SD 10.34). Mean scores fell into the "some mild symptoms" and "serious symptoms" categories, respectively (Table 6).

The LoF also showed an association between better function and work readiness (Table 6). There was a correlation of 0.62 between better function and work readiness, and a greater proportion of patients ready to work achieved higher LoF ratings. All patients but 1 rated ready to work were in the "moderate" $(55.7 \%)$ and "slight" (43.2\%) impairment categories. Patients rated not ready to work were categorized as "moderate" (38.4\%), "severe" (42.0\%), and "most severe" (13.4\%).

The mean NSA-4 total score was significantly lower $(p<0.0001)$ in patients rated ready to work $(11.6, \mathrm{SD}$ 3.28 ) versus not ready to work (14.7, SD 3.97), reflecting lesser severity of negative symptoms in ready to work patients (Table 6).

The CGI-S-N mean was significantly lower $(p<0.0001)$ in patients rated ready to work $(3.2, \mathrm{SD} 0.8)$ versus not ready to work (4.1, SD 0.9), reflecting lesser severity of global negative symptoms in ready to work patients (Table 6).

Agreement between current work and work readiness status showed $70 \%$ sensitivity, $63 \%$ specificity, $32 \%$ positive predictive value (PPV), and $89 \%$ negative predictive value (NPV) (Table 7).

Cronbach's $\alpha$ showed good internal consistency for the initial 7 items $(\alpha=0.89)$. Inclusion of the final 
TABLE 5. Study 3: Patient demographics by work readiness status

\begin{tabular}{|c|c|c|c|}
\hline \multirow[b]{2}{*}{ Parameter } & & \multicolumn{2}{|c|}{ Work readiness status } \\
\hline & & Ready for work & Not ready for work \\
\hline \multirow[t]{2}{*}{ Gender } & Male, n (\%) & $53(60.2)$ & $84(75.0)$ \\
\hline & Female, $n(\%)$ & $35(39.8)$ & $28(25.0)$ \\
\hline Age & Mean (SD) & $44.6(12.03)$ & $45.6(12.07)$ \\
\hline \multirow[t]{3}{*}{ Work status } & Independent work, n (\%) & $28(31.8)$ & $13(11.6)$ \\
\hline & Supported work, n (\%) & $5(5.7)$ & $4(3.6)$ \\
\hline & Unemployed, n (\%) & $55(62.5)$ & $95(84.9)$ \\
\hline \multirow[t]{7}{*}{ Education } & Some primary/elementary school & $9(10.2)$ & $12(10.7)$ \\
\hline & Some high school & $20(22.7)$ & $24(21.4)$ \\
\hline & Vocational school or certificate program & $2(2.3)$ & $3(2.7)$ \\
\hline & High school diploma or equivalent & $22(25.0)$ & $43(38.4)$ \\
\hline & Some college & $20(22.7)$ & $23(20.5)$ \\
\hline & College or university degree (2- or 4-year) & $13(14.8)$ & $5(4.5)$ \\
\hline & Graduate degree & $2(2.3)$ & $2(1.8)$ \\
\hline
\end{tabular}

SD = standard deviation

TABLE 6. Mean difference in function and negative symptom severity by work readiness status

\begin{tabular}{lccc} 
& \multicolumn{2}{c}{ Work readiness status Mean (SD) } & \\
\cline { 2 - 3 } Variable & Ready for work & Not ready for work & \multirow{2}{*}{ t test p value } \\
\hline GAF score & $61.8(9.39)$ & $48.0(10.34)$ & $<0.0001$ \\
NSA-4 total score & $11.6(3.27)$ & $14.7(3.97)$ & $<0.0001$ \\
CGI-S-N score & $3.2(0.80)$ & $4.1(0.89)$ & $<0.0001$ \\
\hline
\end{tabular}

CGI-S-N = Clinical Global Impression of Severity of Negative Symptoms; $\mathrm{GAF}=$ Global Assessment of Functioning; NSA-4 $=$ Negative Symptom Assessment, 4 -item version; $\mathrm{SD}=$ standard deviation.

dichotomous work readiness question increased internal consistency slightly $(\alpha=0.91)$, while item deletion did not result in any marked change in $\alpha$ (range 0.87-0.9).

\section{Study 3: Relationship between WoRQ items and overall rating}

Logistic regression showed that 2 items-impulse control (\#4) and interference of current symptoms (\#7)-were significantly associated with the final work readiness judgment, accounting for $60 \%$ of the variance. Backward selection, wherein we removed the least significant item, resulted in the retention of just these 2 items in the model as still significant at the 0.05 level (Table 8).

\section{Discussion}

The WoRQ, as established in patients with broad symptom severity, has suitable psychometric properties for use in a clinical trial setting to assess patients' potential to work.
TABLE 7. Analysis of agreement between current work status and work readiness status (current work status "Yes" corresponds to patients working independently ONLY, and sheltered employment has been converted to current work status "No")

Measure of accuracy

Estimate

Sensitivity ${ }^{a}$

0.70

Specificity ${ }^{b}$

0.63

$\mathrm{PPV}^{\mathrm{C}}$

$\mathrm{NPV}^{\mathrm{d}}$

0.32

0.89

$\mathrm{NPV}=$ negative predictive value; PPV = positive predictive value.

a Proportion of patients ready to work among those who are employed.

${ }^{b}$ Proportion of patients not ready to work among those who are unemployed.

${ }^{c}$ Proportion of employed patients among those who are ready to work.

${ }^{d}$ Proportion of unemployed patients among those who are not ready to work.

These diagnostic tests consider current work status as "gold standard," and work readiness as "test outcome."

Practicing clinicians worldwide endorsed the concepts in the WoRQ: treatment adherence, physical appearance, social competence, and symptom control. Specific items addressing patient's insight and willingness to work (concepts also endorsed by the validity panel) were considered implicit in the WoRQ items. Indeed, logistic regression showed a significant association of impulse control (impulse control when interacting with authority figures, peers or coworkers, and potential customers) and interference of current symptoms items with the final readiness judgment, confirming their importance. The WoRQ may be conceptualized as an ordered evaluation moving from basic to more complex functions with a more direct relation to work and symptom severity. Thus, items later in the scale will be more closely related to the final decision but may overlap with earlier items. Early items may provide a foundation for late-item judgments. 


\begin{tabular}{|c|c|c|c|c|}
\hline \multirow[b]{2}{*}{ WoRQ item } & \multirow[b]{2}{*}{ Odds ratio } & \multicolumn{2}{|c|}{ 95\% Confidence interval } & \multirow[b]{2}{*}{$\mathrm{p}$ value } \\
\hline & & Lower & Upper & \\
\hline 1. The patient generally adheres to a treatment plan including medication. & 0.944 & 0.233 & 3.825 & 0.9359 \\
\hline 2. The patient is able to carry out activities of daily living. & 0.893 & 0.248 & 3.219 & 0.8623 \\
\hline 3. The patient is able to consistently keep appointments and schedules with only minimal assistance. & 0.596 & 0.162 & 2.189 & 0.4354 \\
\hline $\begin{array}{l}\text { 4. The patient would have adequate impulse control when interacting with authority figures, peers or } \\
\text { coworkers, and potential customers. }\end{array}$ & 0.360 & 0.131 & 0.989 & $0.0475^{\mathrm{a}}$ \\
\hline 5. The patient's behavior would not make others uncomfortable in a work situation. & 0.940 & 0.304 & 2.904 & 0.9142 \\
\hline 6. The patient's appearance would not make others uncomfortable in a work situation. & 0.571 & 0.216 & 1.509 & 0.2581 \\
\hline 7. The patient's current symptoms would not interfere with the ability to hold a job. & 0.026 & 0.008 & 0.083 & $<0.0001^{\mathrm{a}}$ \\
\hline
\end{tabular}

WoRQ $=$ Work Readiness Questionnaire.

antra-class correlation coefficients according to Shrout and Fleiss's notation.

The items were internally consistent. Reliability was adequate; the final readiness decision showed good test-retest and moderate inter-rater reliability. There was support for improved inter-rater reliability from Session I to Session II among the psychiatrists who rated videos, which suggests that scale familiarity may be important for reliable ratings.

Work readiness was associated with significantly higher levels of functioning: on the GAF, this difference reflected a mean GAF score in the "serious symptoms" category for patients who were rated not ready to work, versus "some mild symptoms" for patients who were rated ready to work, with a similar pattern evident for the LoF. Patients who were rated ready to work also showed a lower level of negative symptoms (NSA-4) and global negative symptom severity (CGI-S-N).

The performance-based UPSA has shown to be predictive of work status and associated with other employment-related measures. For employment status, the UPSA-B has demonstrated low PPV (36\%) but strong NPV (87\%) (sensitivity was $75.9 \%$ and specificity was $59.0 \%) .^{8}$ Similarly, the WoRQ showed low PPV (32\%) but strong NPV (89\%). For the UPSA-B, this result was attributed to a greater ability to identify patients unable to work versus able to work. For both scales, an added consideration is the availability of work and the probability that some patients able to work are unable to obtain employment, leading to misclassification. A possible advantage of the WoRQ is the use of a binary (yes/no) evaluation not reliant on a cut score. Mausbach et $\mathrm{al}^{8}$ used receiver operating characteristic curves to identify the most sensitive cut scores in order to evaluate work status, but acknowledged sample homogeneity (high levels of education, low levels of psychosis, Ashkenazi Jewish ethnicity) as a possible flaw. Thus, findings may be population-dependent, and cut scores may not be broadly applicable. The WoRQ underscores the importance of social competence evidenced by collaborative ability and impulse control as a necessary prerequisite for work readiness, while the UPSA focuses on daily living activities to indicate functional capacity. Thus, the WoRQ may have broader application across different cultures and heterogeneous populations. Finally, the WoRQ is easy to use and requires an average completion time of $<5$ minutes, which is shorter than the UPSA-B (10-15 minutes).

The WoRQ may not be equally applicable to schoolage and retirement-age patients, given its focus on work defined as "any useful activity that could merit pay." Furthermore, although Study 3 recruited patients in the U.S., Sweden, and Argentina, they were predominantly Caucasian or African American. Evaluation of the WoRQ in wider multinational and cross-cultural samples is important to its future development for clinical trial use. Additionally, question content was not strongly supported by regression analyses, despite qualitative endorsement, possibly reflecting the ordered structure of the questionnaire. Thus, there may be modifications to the preceding item content that may help in final clinical evaluation, including explicit use of such concepts as motivation/desire to work and insight into psychiatric status. The NSA-4 scores, which distinguished those ready to work from those not, contains 2 items assessing decreased social drive and interests. Cognitive function also was not considered, but has been associated with employment status ${ }^{17}$ and may affect work readiness. These findings were based on cognitive task performance, and clinical evaluation of cognition may not show the same association. Interpreting data relating work status to the WoRQ is complicated by work subcategories. Although the WoRQ focuses on readiness for "unsupported" paid work, factors such as full- versus part-time, skilled versus unskilled, and the level of autonomy for patients in work were not specifically considered. Such comparisons would require evaluation in a larger sample. Finally, it should be acknowledged that since the intent of the questionnaire is to employ it as a research tool to determine readiness for full-time 
employment, that merits pay, and does not require an unusual level of supervision, the work readiness judgment is not intended to evaluate eligibility for supported work. Desire to work may be key in selecting individuals who can benefit from supported employment and other vocational rehabilitation approaches. ${ }^{18}$

\section{Conclusion}

In conclusion, the WoRQ is a valid tool for use in evaluating patients' readiness to work or conduct a useful activity meriting pay. It is an ordered evaluation that includes social competence, collaborative ability, and impulse control. It has the potential to evaluate a key aspect of recovery/functional remission in clinical practice, independent of the availability of paid employment. The sensitivity of WoRQ to therapeutic effects requires investigation. Also, longer-term data are needed to understand the predictive value of WoRQ to finding a job or conducting a useful activity.

\section{Disclosures}

This work was supported by F. Hoffmann-La Roche. Steven G. Potkin has received grant support, funding, honoraria, or has been a paid consultant to the following companies: Amgen, Bristol-Myers Squibb, Concert Pharmaceuticals, Eli Lilly, Forum Pharmaceuticals, Genentech, Janssen Pharmaceutical, Lundbeck, Merck, Novartis, Otsuka, Sunovion, Roche, Takeda Pharmaceuticals International, Takeda Global Research and Development, and Toyama Pharmaceuticals. Jelena Kunovac has received grant support, funding, honoraria, or has been a paid consultant to the following companies: Otsuka and Sunovion. Dragana Bugarski-Kirola, Sherif Soliman and George Garibaldi are full-time employees of F. Hoffmann-La Roche. Chris J. Edgar and Stephanie Le Scouiller are full time employees of Roche Products Ltd. Eugenio Miguel Velasco does not have anything to disclose.

\section{REFERENCES:}

1. Karagianis J, Novick D, Pecenak J, et al. Worldwide-Schizophrenia Outpatient Health Outcomes (W-SOHO): baseline characteristics of pan-regional observational data from more than 17,000 patients. Int J Clin Pract. 2009; 63(11): 1578-1588.

2. Haro JM, Novick D, Bertsch J, Karagianis J, Dossenbach M, Jones PB. Cross-national clinical and functional remission rates:
Worldwide Schizophrenia Outpatient Health Outcomes (W-SOHO) study. Br J Psychiatry. 2011; 199(3): 194-201.

3. World of Work Report. 2012. International Labour Organization, Geneva, Switzerland; http://www.ilo.org/global/research/globalreports/world-of-work/2012/lang-en/index.htm.

4. Thornicroft G, Tansella M, Becker T, et al. The personal impact of schizophrenia in Europe. Schizophr Res. 2004; 69(2-3): 125-132.

5. Kuhnigk O, Slawik L, Meyer J, Naber D, Reimer J. Valuation and attainment of treatment goals in schizophrenia: perspectives of patients, relatives, physicians, and payers. J Psychiatr Pract. 2012; 18(5): 321-328.

6. Tsang HW, Leung AY, Chung RC, Bell M, Cheung WM. Review on vocational predictors: a systematic review of predictors of vocational outcomes among individuals with schizophrenia: an update since 1998. Aust N Z J Psychiatry 2010; 44(6): 495-504.

7. Cardenas V, Mausbach BT, Barrio C, Bucardo J, Jeste D, Patterson T. The relationship between functional capacity and community responsibilities in middle-aged and older Latinos of Mexican origin with chronic psychosis. Schizophr Res. 2008; 98(1-3): 209-216.

8. Mausbach BT, Depp CA, Bowie CR, et al. Sensitivity and specificity of the UCSD Performance-based Skills Assessment (UPSA-B) for identifying functional milestones in schizophrenia. Schizophr Res. 2011; 132(2-3): 165-170.

9. Potkin SG, Gharabawi GM, Greenspan AJ, et al. Psychometric evaluation of the Readiness for Discharge Questionnaire. Schizophr Res. 2005; 80(2-3): 203-212.

10. Jones SH, Thornicroft G, Coffey M, Dunn G. A brief mental health outcome scale-reliability and validity of the Global Assessment of Functioning (GAF). Br J Psychiatry. 1995; 166(5): 654-659.

11. Strauss JS, Carpenter WT Jr. Prediction of outcome in schizophrenia. III. Five-year outcome and its predictors. Arch Gen Psychiatry. 1977; 34(2): 159-163.

12. Alphs L, Morlock R, Coon C, van Willigenburg A, Panagides J. The 4-Item Negative Symptom Assessment (NSA-4) instrument: a simple tool for evaluating negative symptoms in schizophrenia following brief training. Psychiatry (Edgmont) 2010; 7(7): 26-32.

13. Haro JM, Ochoa S, Gervin M, Mavreas V, Jones P. Assessment of remission in schizophrenia with the CGI and CGI-SCH scales. Acta Psychiatr Scand. 2007; 115(2): 163-164; author reply 164.

14. Shrout PE, Fleiss JL. Intraclass correlations: uses in assessing rater reliability. Psychol Bull. 1979; 86(2): 420-428.

15. Cronbach LJ. Coefficient alpha and the internal structure of tests. Psychometrika 1951; 16(3): 297-334.

16. Nunnally JC, Bernstein IH. Psychometric Theory, 3rd ed. New York: McGraw-Hill; 1994.

17. August SM, Kiwanuka JN, McMahon RP, Gold JM. The MATRICS Consensus Cognitive Battery (MCCB): clinical and cognitive correlates. Schizophr Res. 2012; 134(1): 76-82.

18. Campbell K, Bond GR, Drake RE. Who benefits from supported employment? A meta-analytic study. Schizophr Bull. 2011; 37(2): 370-380. 